\title{
SUPPORTING AND TREATING FAMILIES WITH CHILDREN ON THE AUTISTIC SPECTRUM: THE UNIQUE ROLE OF THE GENERALIST PSYCHOLOGIST
}

\author{
JENNIFER HILLMAN \\ Pennsylvania State University, Berks College
}

\section{Research findings indicate that inten- sive behavior therapy (e.g., applied} behavioral analysis, or ABA) represents an effective treatment for autistic spectrum disorders. Unfortunately, children with autism represent an underserved patient population. Parents often make treatment decisions with insufficient information and report problems in establishing and maintaining treatment programs. This practice review asserts that psychologists, including those without professional certification or coursework in $A B A$, are in a unique position to assist affected children and their families. Psychologists can provide critical information about evidence-based treatment; offer assistance in overcoming barriers to intensive treatment, including personnel selection; and provide ongoing support to family members. Case examples also illustrate how psychologists can help families address specific barriers to intensive treatment.

Keywords: autism, autistic spectrum disorders, behavior therapy, evidencebased, family therapy, intervention

Jennifer Hillman, Department of Psychology, The Pennsylvania State University, Berks College.

This project was supported, in part, by a Faculty Research and Development Grant awarded by the Pennsylvania State University.

Correspondence regarding this article should be addressed to Jennifer Hillman, Applied Psychology Program, Penn State Berks, P.O. Box 7009, Reading, PA 19610. E-mail: JLH35@psu.edu
Autism is a devastating developmental disorder in which children present with core deficits in verbal and nonverbal communication, social interaction, and pretend or imaginative play. As articulated in the Diagnostic and Statistical Manual of Mental Disorders (4th ed., text rev.; American Psychiatric Association, 2000), typical problems are observed regarding limited eye contact, an absence of appropriate facial expressions and gestures, a lack of developmentally appropriate peer relationships, an absence of shared attention, and a general lack of emotional or social reciprocity. Children with autism also typically maintain restricted or repetitive behaviors, interests, and activities; inflexible adherence to nonfunctional rituals; and stereotypical and repetitive movements (e.g., hand flapping) known as "stimming." No one behavior serves as a definitive diagnostic indicator; children with autism present with a variety of symptoms across cognitive, emotional, and behavioral domains (also see Kabot, Masi, \& Segal, 2003). Language and nonverbal communication skills are either absent or significantly delayed (American Psychiatric Association, 2000). Autism spectrum disorders also include pervasive developmental disorder not otherwise specified (PDD-NOS), which is sometimes referred to as high-functioning autism, and Asperger's syndrome, in which affected individuals typically do not display the early language deficits inherent in autistic disorder (Volkmar, Lord, Bailey, Schultz, \& Kiln, 2004). For purposes of this practice review, I use the term autism broadly to represent the spectrum of autistic disorders, including autistic disorder, PDDNOS, and Asperger's syndrome.

My goal in this practice review is to highlight the unique and essential role that generalist psychologists can play in supporting and treating families coping with childhood autism, particularly within the context of evidence-based treatment. Although estimates suggest that 1 out of 166 children have an autism spectrum disorder (Chakrabarti \& Fombonne, 2001), children with 
autism represent an underserved patient population (Kasari \& Rotheram-Fuller, 2005). Parents often make treatment choices for their child on the basis of limited or incorrect information (e.g., Romanczyk \& Gillis, 2005), and those who elect to engage in evidence-based intensive behavior therapy, such as applied behavior analysis (ABA; see Smith, 1999), report significant difficulties in establishing and maintaining treatment programs (Johnson \& Hastings, 2002). Even without specialized training or certification in ABA, psychologists can aid affected families in three primary ways. First, psychologists can become informed about ABA and its primary features and convey this critical information to parents and family members. Second, psychologists can help families establish an appropriate treatment team and address typically overlooked barriers to intensive treatment, including personnel selection, treatment team turnover, boundary disturbances, parental confusion regarding general behavioral principles, difficulty interfacing with school personnel, and the presence of mental illness or family dysfunction. Third, psychologists are uniquely qualified to provide integrative, ongoing mental health support to family members, particularly within the context of a systems perspective. Case examples also illustrate how psychologists can help parents and family members address specific barriers to treatment.

\section{Evidence-Based Treatment Recommendations}

One form of therapy that has achieved some measure of success in addressing core deficits in autism is that of intensive behavioral therapy, commonly referred to as ABA (cf. Kabot et al., 2003). (Although ABA represents a type of behavior therapy initially developed for treatment of childhood autism [Lovaas, 1987], in this article I use the terms intensive behavioral therapy and $A B A$ interchangeably.) ABA's short- and long-term effectiveness with children on the autistic spectrum has been documented repeatedly by its founder, Ivar Lovaas (Lovaas \& Smith, 2003; McEachin, Smith, \& Lovaas, 1993), and others (Eikeseth, Smith, Jahr, \& Eldevik, 2002; Howard, Sparkman, Cohen, Green, \& Stanislaw, 2005; Sallows \& Graupner, 2005; Smith, Groen, \& Wynn, 2000) in both center- and home-based programs (Smith, 1999). The majority of these studies involved preschool and school-age chil- dren diagnosed with autism or PDD-NOS (e.g., "high-functioning" autism). Although there is some debate over the distinction between highfunctioning autism and Asperger's syndrome, general consensus suggests that children with either diagnosis are likely to benefit from intensive behavioral treatment (Kasari \& Rotheram-Fuller, 2005). Outcome data suggest that if a child receives intensive treatment (i.e., if behavioral therapy is delivered one-on-one for at least $25-40 \mathrm{hr}$ a week) based on ABA principles that emphasize the generalization of positive behaviors and skills across a variety of settings, in collaboration with parents, positive outcomes are typically obtained (Erba, 2000).

Reviews of the literature (e.g., Kabot et al., 2003; Smith, 1999) suggest that preschool and elementary-school-age children with an autism spectrum disorder, including children with limited language skills, who received such intensive, in vivo behavioral therapy for at least 1 year demonstrated, via standardized testing, modest to significant increases in cognitive functioning (e.g., IQ), language and social skills, and adaptive functioning when compared with children in control or comparison groups that included small group instruction, fewer hours of intervention, or only parent-based treatment delivery (e.g., Howard et al., 2005; Sallows \& Graupner, 2005; Smith et al., 2000; Weisz, Sandler, Durlak, \& Anton, 2005). In a number of studies, nearly half of the children were reported to function in typical rather than special education classes after intervention (Lovaas, 1987; Sallows \& Graupner, 2005; Smith et al., 2000).

Follow-up studies (e.g., McEachin et al., 1993) have suggested that many children may maintain gains into adolescence. ABA programs have also been modified to emphasize acquisition of language (verbal behavior analysis; Sundberg \& Partington, 1998), social and play skills (Smith et al., 2000), and self-control and limit setting in both home- and school-based settings (Sugai et al., 2000). Another benefit of ABA is that parents have reported generally high levels of satisfaction with intensive behavioral programs and lower levels of stress during their child's treatment (Smith et al., 2000). Despite all of these positive attributes, it is also important to note that ABA is not a panacea or cure-all. Not all children respond equally well, particularly those who have lower IQ scores or limited language skills at the beginning of treatment (Shea, 2004; Sherer \& 
Schreibman, 2005). However, early intervention, which should take place as early as possible after diagnosis (Kabot et al., 2003), even among children as young as 1 to 2 years of age, appears essential to achieve a greater likelihood of success (e.g., Smith, 1999).

Consistent with these research findings and expert agreement (Kabot et al., 2003), Division 33 (Mental Retardation and Developmental Disabilities) of the American Psychological Association (1989), the American Academy of Pediatrics (2001), and the New York State Department of Health Early Intervention Program (1999) have formally recommended intensive behavior therapy as a primary, evidence-based treatment for autism. In their practice guidelines, the Surgeon General's Office of the United States has called for 30-40 hr a week of one-on-one, intensive behaviorally based treatment (U.S. Department of Health \& Human Services, 1999). In a number of states, departments of health and human services have identified ABA as a basic entitlement for children with autism (Mulick \& Butter, 2002).

Various studies have suggested that eclectic approaches to treatment result in less effective outcomes (Kabot et al., 2003), particularly when intensive behavioral therapy is not the primary modality (e.g., Howard et al., 2005; Jacobson, 2000; Weisz et al., 2005). The National Institute of Mental Health (1975) has also warned that using psychodynamic or insight-oriented psychotherapy alone as a treatment for autism is generally ineffective. Thus, it would appear to benefit both psychologists and their clients to maintain general knowledge of $\mathrm{ABA}$ and its essential characteristics.

\section{Concerns Related to Parental Knowledge and Treatment Selection}

Since the initial reauthorization of the Individuals With Disabilities Education Act (Individuals With Disabilities Education Act Amendments of 1997, Individuals With Disabilities Education Improvement Act of 2004), parents are expected to participate fully in the formulation of their child's early intervention and school-age special education treatment plans (Feinberg \& Vacca, 2000) but must often make complex decisions about their child's treatment goals and interventions on the basis of only a limited, or selectively presented, amount of information (Romanczyk \&
Gillis, 2005). For example, the majority of parents in a recent study maintained only limited knowledge of effective psychologically based treatment options and assumed that biomedical interventions were of primary importance (Furnham \& Buck, 2003). In a survey of more than 500 parents, negative experiences reported both inside and outside of the educational system included significant difficulties in gathering information about treatment options and then obtaining and monitoring related services (Johnson \& Hastings, 2002; McWilliam, Lang, Vandiviere, \& Angell, 1995). Consistent with these reported parental problems, estimates suggest that fewer than $10 \%$ of children with autism receive appropriate, intensive behavioral treatment (Ruble, Heflinger, Renfrew, \& Saunders, 2005).

It also remains unclear to what extent psychologists without specialized training in autism convey to parents correct knowledge about treatment options. An exploratory study showed that generalist psychologists were significantly less likely to endorse appropriate special education services for children with autism than were specialty providers (Heidgerken, Geffken, Modi, \& Frankey, 2005). For parents to engage effectively in treatment selection and delivery for their developmentally compromised child, they must be empowered with factual knowledge and information about effective, research-based behavioral treatments (Kabot et al., 2003). Informed psychologists can be instrumental in relaying this information.

\section{Suggestions for Personnel Selection}

Specialized training is required to implement and direct an $\mathrm{ABA}$ program. After completing a specialized graduate program in ABA and other forms of intensive behavioral therapy and passing a national examination, qualified individuals are referred to as board-certified behavior analysts or as behavioral specialists, certified (BSCs). BSCs typically train and supervise other individuals, commonly referred to as therapeutic support staff or paraprofessionals, who actually conduct the majority of treatment itself. In many ABA programs, those paraprofessionals are not required to hold even a bachelor's degree.

Psychologists can effectively counsel parents to select a BSC who meets certain basic criteria. First, parents should know that a licensed psy- 
chologist is not necessarily a qualified or certified BSC. A good BSC will be board certified, follow the American Psychological Association's (APA's) Ethical Principles of Psychologists and Code of Conduct (APA, 2002) whether she or he is a licensed psychologist or not (Rotholz \& Jacobson, 2000), have more than $80 \mathrm{hr}$ of internship training in ABA working directly with children with autism, and be available for behavioral emergencies. Parents should be cautioned to avoid a professional who promises a generic or "one-size-fits-all" approach to treatment (Kabot et al., 2003). Developing an individualized ABA program requires that a $\mathrm{BSC}$ spend numerous hours with a child to first observe and then assess that child's skills and behaviors in various environments (e.g., school, home; Carr et al., 2002). Consistent with comprehensive, positive behavior support (Carr et al., 2002), another sign of a qualified BSC is a primary focus on skill development rather than problem behavior (Rotholz \& Jacobson, 2000).

\section{The Untapped Role of Psychologists in Addressing Barriers to Treatment}

Although the vast majority of reports involving the clinical outcomes for ABA-based programs are positive, parents have reported significant difficulty in their attempts to initiate and implement such intensive programs (McWilliam et al., 1995). Despite the identification of specific treatment barriers through qualitative analyses of parent interviews (Johnson \& Hastings, 2002), virtually no guidelines have been offered to suggest how psychologists can interface with families engaged in ABA programs to avoid or combat such challenges. The following information and case examples represent a formal attempt to illustrate how psychologists can assist parents and other family members as they implement and sustain intensive behavioral programs.

\section{Limited Personnel and Financial Resources}

A primary barrier to requisite, intensive behavioral therapy for a child with autism is the difficulty of locating and then funding the services of an appropriately trained BSC and a related team of paraprofessionals (Johnson \& Hastings, 2002). In many parts of the United States and in most of the United Kingdom, the demand for qualified BSCs greatly exceeds the available supply. The total cost of providing $40 \mathrm{hr}$ a week of one-onone intervention can also reach $\$ 40,000$ a year (Feinberg \& Vacca, 2000), and private insurance rarely provides reimbursement. The cost of even $15 \mathrm{hr}$ a week of ABA can be high; many BSCs charge between $\$ 50$ and $\$ 150$ per hour, and paraprofessional fees often range from $\$ 7$ to $\$ 15$ per hour. Additional time and money is typically needed for parent education, documentation and charting, and supervision of paraprofessionals.

Thus, parents must often make difficult decisions about hiring treatment staff. Problems can arise when there are few BSCs available in a geographic area or if funding is limited. A psychologist can help parents examine alternatives and make informed choices regarding difficult decisions about how to spend limited time and resources. For example, if a board-certified BSC is not available or the fees are deemed too costly, a behavioral consultant who is otherwise qualified but has not taken the licensing exam may be a good substitute. Because the paraprofessionals who typically conduct the one-on-one therapy with children do not require any formal coursework or academic degree, family members, friends, neighbors, grandparents, college students, day care providers, and other volunteers can also be trained to play this critical role, either at no cost or for a fraction of the typical cost. Parents can also be advised to contact their local college to see if undergraduate psychology and special education students are being trained in ABA within the context of a clinical internship or teaching practicum and are available as paraprofessionals for a substantially reduced fee.

Of equal importance, psychologists can help family members grieve the loss of what may have otherwise been financial security, early retirement, or a yearly summer vacation. For other families, the money needed to fund an ABA program may mean moving to a significantly smaller house or apartment, taking out a second mortgage, taking a second or third job, or wearing second-hand clothing. Having to shunt so much of the family's income toward intensive behavioral treatment for one child with autism can lead to intense feelings of anger and depression. Psychologists can also help parents and siblings cope with related feelings of guilt when one child in the family receives a significantly greater share of financial resources than another. There is no right answer about how clients should manage their money, but psychologists can help 
clients communicate openly with one another about how they plan to allot valuable resources.

Case example. One psychologist described a client's anger and frustration. A father, Pat, pondered,

Should we go on a family vacation with all of our children, or do we stay home and use the extra money to get Jason [his 4-year-old son with autism] a BSC instead of doing all of this ABA stuff ourselves? I mean, there's just not enough time and money to go around. . . . I've already accepted the fact that I will never be a rich man, but how do you choose between your kids like that?

Helping parents involve siblings in the discussion, either informally or within the context of a specially scheduled family session, can also be of value in certain circumstances.

During a subsequent family session in which Pat admitted to his family that they simply did not have the same amount of disposable income as in previous years, Jason's sister, Anna, remarked to her father, "Dad, I didn't know money was so tight. You never told us; I just thought things were the same.... You know, it's OK with me if we don't go on vacation this year. I mean, if I needed help, I know you would do it for me, too." The family also decided jointly that they would take a few day trips to the beach and go to the movies more often instead. As a result, Pat felt that he did not have to spend as much effort trying to prove to himself and his family that he "was a real man." It was more than sufficient to be a "good-enough" father instead of a wealthy man.

\section{Absenteeism and High Rates of Turnover Among Treatment Team Members}

Even when parents locate and hire an appropriate BSC and team of paraprofessionals, the typically low rate of pay for paraprofessionals almost ensures a high rate of absenteeism and turnover. Even clinicians who run center-based ABA programs admit it can be formidable to provide staffing for a full complement of treatment hours (Smith et al., 2000). It can be emotionally devastating to parents who become attached to a skilled, empathic paraprofessional when she or he quits without notice, graduates from school, or takes a new job. For children with autism who have difficulty with transitions, adjusting to a reduction in hours of ABA and then a new paraprofessional is likely to result in anxiety, frustration, and anger, including related be- havioral setbacks. A psychologist can help parents process their feelings of anger and loss and also help the child with autism find some way to prepare for, or at least acknowledge, the termination. A psychologist can also help parents recognize that the loss of one paraprofessional and the introduction of another may, after a period of adjustment, present an opportunity for their child to generalize his or her learning and experience positive gains and feelings with other people.

\section{Disruptions in Therapeutic Boundaries}

When families become involved in ABA programs that may include up to $40 \mathrm{hr}$ per week of in vivo therapy, a number of boundary issues are likely to arise. These potential barriers to treatment may include problems with enmeshment, inappropriate disclosure of information, and dual relationships. With many home-based ABA programs, a family's overall sense of structure and privacy can be challenged.

Case example. One family had a paraprofessional arrive weekday mornings at 8:30 a.m. to help their 5-year-old son, Tyler, prepare for school and transition to morning sessions of ABA at school. Another paraprofessional arrived home with their son shortly after noon, and then another arrived to continue therapy around 4:00 p.m. The last paraprofessional of the day departed at 6:30 p.m. To provide even greater continuity of care, the family hired a paraprofessional to work with their son at home on Saturday from 9:00 a.m. to 1:00 p.m. Although Tyler was making significant gains, his mother, Bonnie, made an appointment with a psychologist because she was "losing her mind."

With the help of her new psychologist, Bonnie was able to express her sadness and anger about losing her private time, and even the ability "to go to the bathroom in my own house without always asking if it was OK first." Bonnie's therapist also helped her realize that she didn't have to be "on" or exceedingly happy all of the time with her paraprofessionals or give in to unrealistic pressure on herself to have her home spotlessly clean. After much discussion, she and her husband also decided that they would limit Tyler's weekend therapy sessions to only twice a month and monitor his progress closely to see if he was able to maintain his gains without the additional sessions. Bonnie's psychologist also helped her practice more effective ways to com- 
municate with her son's BSC to help manage some of these issues and concerns.

Another common problem experienced by families with ABA programs is the somewhat fluid boundaries often encountered between clients, paraprofessionals, and family members as a result of intense in vivo treatment, often in the family's home. In addition to parents' feeling encroached on, many paraprofessionals are likely to feel overwhelmed and unprepared when a family member reveals family secrets or describes depressive symptoms or if they witness constant fighting or verbal abuse between family members and their children. In many cases, individual psychologists can help parents recognize the need for boundaries between their own family members and members of their child's treatment team and explain how these boundaries actually assist paraprofessionals in providing better care for their children. Typically, psychologists empower family members to communicate their needs and concerns more effectively with their team of paraprofessionals.

Probably the most common boundary problem experienced by parents and paraprofessionals is that of enmeshment and dual relationships. Some paraprofessionals find themselves having lunch and dinner with their "families," then going along to family functions to help with behavior management, and then crossing the line into informal socializing and even babysitting. Although paraprofessionals are not necessarily bound by formal APA guidelines, dual relationships are clearly to be avoided. In extreme instances, a paraprofessional may make or receive inappropriate romantic or sexual advances from a child's parent or relative. Although no empirical data are available to indicate the extent to which such boundary disturbances do occur, this phenomenon may be more common than initially believed, particularly owing to the tremendous pressures placed on parental relationships (e.g., Higgins, Bailey, \& Pearce, 2005). A psychologist can help parents recognize and examine such boundary disturbances when they occur and empower parents to address the issue directly with their paraprofessional.

Case example. Ginny, the mother of a child with autism, became very close with her son's paraprofessional, Amber.

It was like we became fast friends. We had so many interests in common.... It was great to have her stay late for dinner when my husband had to work late, and having her baby sit was a dream.... I just didn't understand when Amber stopped wanting to stay late and come over.

After a while, Amber's attendance wavered with little explanation, and when pressed, Amber resigned despite Ginny's pleas. In psychotherapy, Ginny was able to articulate,

Yeah, I guess I always wanted a "typical" daughter, and it seemed like Amber was it. It was just so easy to talk to her and go places with her. ... In the end, I guess it made it hard for her to be honest with me if she got upset about scheduling or something my son did. I guess that wasn't fair for me to treat her that way, even if it sort of felt good to both of us at first.

In therapy, this mother was able to acknowledge and work through her own desire to have a typical child. As a result, she also became less emotionally reliant on her relationships with her son's paraprofessionals and was able to strengthen her existing relationships with friends.

\section{Parental Confusion Regarding Behavioral Principles}

Barriers to intensive behavioral treatment for childhood autism can also include family members' resistance to treatment, which often arises from confusion or a lack of knowledge regarding basic tenets of behavioral therapy. A typical challenge that some parents experience is a resistance to ABA-based therapy due to its "nonemotional" behaviorist approach. It is critically important to help parents learn that once appropriate behaviors are established through ABA and discrete trial training, the appropriate emotions, cognitions, and language will typically follow.

Case example. As articulated in psychotherapy by Nancy, the mother of Maria, a nonverbal 4-year-old with autism,

I just hate the idea of ABA. I've seen my daughter scream because she has to sit down and do something that I think is kind of stupid. I feel like we are trying to train a dog, for God's sake. I mean, here's some M\&Ms, Maria, do a trick now! It makes me feel sick.

Upon exploration of these issues, Nancy was able to admit that she was terrified that her child was so "beyond reach" and that she was such a bad mother that she had to have outside experts reach her daughter through something so "simple and stupid" as food.

In essence, Nancy's disdain for ABA was driven by intense fears that her daughter would always remain "animal-like" and severely disabled and nonresponsive. She felt upset that she 
could not even reason with her daughter. When her psychologist explained that one can also not necessarily reason with a healthy young toddler, or even many adults when they are under significant stress, Nancy's current expectations became more realistic. After expressing and working through her initial sadness and grief in individual psychotherapy, Nancy was able to allow herself to feel some hope that her daughter would improve over the course of treatment. After acknowledging her fear and grief, Nancy was also able to discuss these issues at length with her daughter's BSC and continue with the ABA program. After a few months of treatment, Maria improved significantly, and to Nancy's pleasure, her daughter was able to benefit from other reinforcers like hugs, tickles, and smiles rather than food. Simple language emerged 4 months later.

Of equal importance in addressing barriers to effective behavioral treatment, psychologists can often help parents better understand the concept of behavioral extinction. In essence, when anyone tries to extinguish a behavior, that behavior will inevitably increase in intensity or frequency before it begins to decrease. Unfortunately, when the frequency of a troubling behavior targeted for extinction, like a tantrum, begins to increase, many parents become disillusioned with ABA and stop or significantly reduce their child's treatment. Although a BSC can provide vital psychoeducation, some may have difficulty explaining these concepts in ways that parents might readily understand, or conversely, some may be so pressed for time that most of it is spent developing $\mathrm{ABA}$ programs rather than providing psychoeducation and support to parents.

Case example. Consider Candy, the mother of 5-year old Johnny, who has autism. With Johnny, it often took $3 \mathrm{hr}$ to get him to bed because of complicated rituals and extended requests for drinks, stories, back rubs, and so forth. With any deviation in these requests, Johnny would fall to the floor, kick his arms and legs, and scream at a higher and higher volume. On recommendation from her BSC, Candy was told to explain to Johnny that he had a new routine and that it would involve a bath, brushing his teeth, getting a drink, selecting and reading one bedtime story, getting a goodnight kiss, and turning off the light-with no exceptions. When Candy implemented this protocol, Johnny had a tantrum and yelled for more than $40 \mathrm{~min}$ in his room. Candy added, “So, I couldn't take it. My husband couldn't take it. I didn't understand why it made it even worse, and we got right back into doing what Johnny wanted."

As Candy noted later in individual psychotherapy,

If I just knew ahead of time that Johnny's tantrums at night would get worse-much worse- before they got better, my husband and I probably would have stuck with it $[\mathrm{ABA}]$. Now that I understand how it works, I realize that we've probably made things worse because we just reinforced his tantrums instead. ... I just wish I was prepared [for the increase in behavior frequency and intensity before extinction].

After a lengthy discussion in couples' therapy and after an informal discussion with her son's BSC, Candy steeled herself for the increase in screaming while Johnny learned to adhere to his new schedule and then go to bed on his own. After a 2-week period, Johnny was able to go to bed on his own after his routine of self-care and a selected bedtime story.

\section{Difficulty Interfacing With School Personnel}

Many children with autism spectrum disorders, including older children and those with fewer language and cognitive limitations, experience significant difficulty maintaining self-control, particularly in school settings. Without the support of teachers and support staff, as well as parents, increasing a child's participation in appropriate behavior can be difficult. The generalist psychologist can be vital in helping individuals who work with autistic children understand that invoking a time-out or creating a behavioral contract does not necessarily promote appropriate behavior. Such "single-dimension" interventions are inconsistent with ABA principles that emphasize the need to identify triggering events and make both environmental and behavioral modifications (Sugai et al., 2000).

Case example. Matt was a verbal, 9-year-old boy who attended his local public school. His teacher complained to his parents that Matt would not sit at his desk but would stand up and sit down repeatedly. This behavior distracted other children, who began to tease Matt. Sending Matt to the principal's office did not seem to help. After discussing the issue with their generalist psychologist, Matt's parents scheduled a conference with his teacher. They later observed Matt in the classroom and hypothesized that sitting near the back of the classroom caused him to become distracted by the children sitting in front. This 
distraction led to frustration and his extraneous movements.

Matt's parents and teacher made a plan to move his seat to the front of the room. Instead of sending him to the principal's office immediately, Matt's teacher agreed to give him a nonverbal sign to alter his inappropriate behavior. Matt was also taught to extend his arms down firmly against the seat of his chair when he felt restless, which allowed him to engage in physical activity that was not disruptive to others. After a few weeks, the number of visits to the principal's office diminished considerably, and Matt reported that he "felt better about school because the kids stopped calling [me] names." His teacher also noted, "I feel like a teacher instead of a disciplinarian. Matt is learning to take charge of himself."

\section{Resistance From Individuals Unaware of Treatment Necessity}

Just as a lack of institutional support can hinder children from obtaining treatment, certain individuals in contact with the child or family members may also inadvertently provide obstacles to treatment. Therapists can help bolster parents' resolve when they encounter comments from other individuals (e.g., friends, relatives, teachers, even health care providers) who are uninformed about the necessity of treatment for autism if they encounter statements such as "Oh, don't worry. That's just him being a boy" or "He'll just outgrow everything in a few years anyway." Unfortunately, the core symptoms of autism do not appear to resolve themselves or abate without treatment (Billstedt, Gillberg, \& Gillberg, 2005).

\section{The Presence of Mental Illness or Family Dysfunction}

The ability of family members to participate fully in a child's treatment can be compromised significantly by the presence of mental illness or family dysfunction. Parents and family members of children with autism are more likely to experience depression, anxiety, high levels of stress (Bitsika \& Sharpley, 2004; Rodrique, Morgan, \& Geffken, 1990), and marital discord (Higgins et al., 2005) than are members of the general population, including family members of children with mental retardation (Dunn, Burbine, Bowers,
\& Tantleff-Dunn, 2001). Because active collaboration and involvement among family members is essential to effective treatment delivery (Kabot et al., 2003), any dysfunction within the family system can diminish treatment outcomes.

\section{Providing Integrated Mental Health Treatment}

Working within the well-established context of a systems perspective for families with chronically ill children (cf. Kazak, 1989), psychologists can encourage family members to engage in individual, couples, group, or family therapy, as appropriate, and engender better treatment and outcomes for their children with autism. Psychologists can also provide crisis intervention and trauma counseling in response to a child's initial diagnosis, ongoing behavioral problems, or related familial discord. It also is important to note that BSCs are not trained or qualified to diagnose or treat any mental health issues among family members or to provide crisis intervention. The role of the BSC is limited to collaboration with family members within the specific context of generating, delivering, and evaluating individualized behavioral interventions for the affected child. Thus, although the participation of a BSC is vital in providing evidence-based, intensive behavioral treatment, the involvement of a psychologist is equally as essential in providing ongoing, integrated clinical support, including appropriate clinical assessment and psychotherapy for affected family members.

\section{Conclusion}

Without the need to obtain additional, formal training, psychologists are in a unique position to help family members implement and sustain the evidence-based, intensive behavioral therapy recommended for the treatment of childhood autism. Conveying accurate information about evidencebased $\mathrm{ABA}$ programs to parents and helping family members avoid barriers to treatment is essential. Such assistance appears vital, as estimates suggest that fewer than $10 \%$ of children with autism receive appropriate treatment services (Ruble et al., 2005). Psychologists can also be advised to network with the BSC to provide comprehensive care to families. Such interventions will allow psychologists to better serve this crit- 
ically important underserved patient population, as well as their affected family members.

\section{References}

American Academy of Pediatrics. (2001). The pediatrician's role in the diagnosis and management of autistic spectrum disorder in children. Pediatrics, 107, 12211226.

American Psychiatric Association. (2000). Diagnostic and statistical manual of mental disorders (4th ed., text rev.). Washington, DC: Author.

American Psychological Association. (2002). Ethical principles of psychologists and code of conduct. American Psychologist, 57, 1060-1073.

American Psychological Association, Division 33. (1989). Guidelines on effective behavioral treatment for persons with mental retardation and developmental disabilities. Psychology in Mental Retardation and Developmental Disabilities, 14, 3-4.

Billstedt, E., Gillberg, C., \& Gillberg, C. (2005). Autism after adolescence: Population-based 13- to 22year follow-up study of 120 individuals with autism diagnosed in childhood. Journal of Autism and Developmental Disorders, 35, 351-360.

Bitsika, V., \& Sharpley, C. F. (2004). Stress, anxiety, and depression among parents of children with autism spectrum disorder. Australian Journal of Guidance and Counselling, 14, 151-161.

Carr, E., G., Dunlap, G., Horner, R. H., Koegel, R. L., Turnbull, A. P., SAIlor, W., et al. (2002). Positive behavior support: Evolution of an applied science. Journal of Positive Behavior Interventions, 4, $4-16$.

Chakrabarti, S., \& Fombonne, E. (2001). Pervasive developmental disorders in preschool children. JAMA, 24, 3093-3099.

Dunn, M. E., Burbine, T., Bowers, C. A., \& TAntlefFDunN, S. (2001). Moderators of stress in parents of children with autism. Community Mental Health Journal, 37, 39-52.

Eikeseth, S., Smith, T., Jahr, E., \& Eldevik, S. (2002). Intensive behavioral treatment at school for 4-7 yearold children with autism. Behavior Modification, 26, 49-68.

ErbA, H. W. (2000). Early intervention programs for children with autism: Conceptual frameworks for implementation. American Journal of Orthopsychiatry, 70, 82-94.

FeinberG, E., \& VACCA, J. (2000). The drama and trauma of creating policies on autism: Critical issues to consider in the new millennium. Focus on Autism and Other Developmental Disabilities, 15, 130-137.

Furnham, A., \& BuCK, C. (2003). A comparison of lay-beliefs about autism and obsessive-compulsive disorder. International Journal of Social Psychiatry, 49, 287-307.

Heidgerken, A. D., Geffren, G., Modi, A., \& Frakey, L. (2005). A survey of autism knowledge in a health care setting. Journal of Autism and Development Disabilities, 35, 323-330.

Higgins, D. J., Bailey, S. R., \& Pearce, J. C. (2005). Factors associated with functioning style and coping strategies of families with a child with an autism spectrum disorder. Autism, 9, 125-137.

Howard, J. S., Sparkman, C. R., Cohen, H. G., Green, G., \& Stanislaw, H. (2005). A comparison of intensive behavior analytic and eclectic treatments for young children with autism. Research in Developemental Disabilities, 26, 359-383.

Individuals With Disabilities Education Act Amendments of 1997, P.L. 105-17, 111 Stat. 37.

Individuals With Disabilities Education Improvement Act of 2004, P.L. 108-446, 20 U.S.C. $\$ 1462$ (h).

JACOBSON, J. W. (2000). Early intensive behavioral intervention: Emergence of a consumer-driven service model. Behavior Analyst, 23, 149-171.

Johnson, E., \& Hastings, R. P. (2002). Facilitating factors and barriers to the implementation of intensive home-based behavioral intervention for young children with autism. Child: Care, Health, and Development, 28, 123-130.

Kавот, S., Masi, W., \& Segal, M. (2003). Advances in the diagnosis and treatment of autism spectrum disorders. Professional Psychology: Research and Practice, $34,26-33$

KASARI, C., \& Rotheram-Fuller, E. (2005). Current trends in psychological research on children with highfunctioning autism and Asperger disorder. Current Opinion in Psychiatry, 18, 497-501.

KAZAK, A. E. (1989). Families of chronically ill children: A systems and social-ecological model of adaptation and challenge. Journal of Counseling and Clinical Psychology, 57, 25-30.

LovAAs, O. I. (1987). Behavioral treatment and normal educational and intellectual functioning in young autistic children. Journal of Consulting and Clinical Psychology, 28, 3-9.

LovaAs, I. O., \& Smith, T. (2003). Early and intensive behavioral intervention in autism. In A. E. Kazdin \& J. R. Weisz (Eds.), Evidence-based psychotherapies for children and adolescents (pp. 325-340.) New York: Guilford Press.

McEachin, J. J., Smith, T., \& LovaAs, O. I. (1993). Long-term outcome for children with autism who received early intensive behavioral treatment. American Journal on Mental Retardation, 28, 359-372.

McWilliam, R. A., LANG, L., Vandiviere, P., \& AnGELL, R. (1995). Satisfaction and struggles: Family perceptions of early intervention. Journal of Early Intervention, 19, 43-60.

Mulick, J. A., \& Butter, E. M. (2002). Educational advocacy for children with autism. Behavioral Interventions, 17, 54-74.

National Institute of Mental Health. (1975). Research in the service of mental health. Rockville, MD: Author.

New York State Department of Health Early Intervention Program. (1999). Clinical practice guideline: Technical manual. Albany, NY: New York State Department of Health.

Rodrique, J. R., Morgan, S. B., \& GefFKen, G. (1990). Families of autistic children: Psychological functioning of mothers. Journal of Clinical Child Psychology, 19, 371-379.

RomAnczyK, R. G., \& Gillis, J. M. (2005). Treatment approaches for autism: Evaluating options and making informed choices. In D. Zager (Ed.), Autism spectrum 
disorders: Identification, education, and treatment (3rd ed.; pp. 515-535). Mahwah, NJ: Erlbaum.

Rotholz, D. A., \& JACOBSON, J. (2000). Behavioral consultants: Who are they and how do I find the right one? Washington, DC: American Association on Mental Retardation, Psychology Division.

Ruble, L. A., Heflinger, C. A., Renfrew, J. W., \& SAUnders, R. C. (2005). Access and service use by children with autism spectrum disorders in Medicaid managed care. Journal of Autism and Developmental Disorders, 35, 3-13.

Sallows, G. O., \& Graupner, T. D. (2005). Intensive behavioral treatment for children with autism: Fouryear outcome and predictors. American Journal on Mental Retardation, 111, 417-438.

SHEA, V. (2004). A perspective on the research literature related to early intensive behavioral intervention (Lovaas) for young children with autism. Autism, 8, 349-367.

Sherer, M. R., \& Schreibman, L. (2005). Individual behavioral profiles and predictors of treatment effectiveness for children with autism. Journal of Consulting and Clinical Psychology, 73, 525-538.

Sмiтh, T. (1999). Outcome of early intervention for chil- dren with autism. Clinical Psychology: Science and Practice, 6, 33-49.

Smith, T., Groen, A. D., \& Wynn, J. W. (2000). Randomized trial of intensive early intervention for children with pervasive developmental disorder. American Journal on Mental Retardation, 102, 238-249.

Sugai, R., Horner, R. H., Dunlap, G., Hieneman, M., Lewis, T. J., Nelson, C. M., et al. (2000). Applying positive behavior support and functional behavioral assessment in schools. Journal of Positive Behavior Interventions, 2, 131-143.

Sundberg, M., \& Partington, J. W. (1998). Teaching language to children with autism or other developmental disabilities. Pleasant Hill, CA: Behavior Analysts.

U.S. Department of Health \& Human Services. (1999). Mental health: A report of the Surgeon General. Rockville, MD: Author.

Volkmar, F. R., Lord, C., Bailey, A., Schultz, R. T., \& KLIN, A. (2004). Autism and pervasive developmental disorders. Journal of Child Psychology and Psychiatry, 45, 135-170.

Weisz, J. R., Sandler, I. N., Durlak, J. A., \& Anton, B. S. (2005). Promoting and protecting youth mental health through evidence-based prevention and treatment. American Psychologist, 60, 628-648.

\section{Correction to Schut et al. (2005)}

In the article "Therapist interpretation, patient-therapist interpersonal process, and outcome in psychodynamic psychotherapy for avoidant personality disorder" (Psychotherapy: Theory, Research, Practice, and Training, 2005, Vol. 42, No. 4, pp. 494-511), the correct legend for Figure 1 on page 500 should read as follows:

Figure 1. The SASB circumplex model, cluster version, interpersonal surfaces. Adapted from Benjamin (1993), Interpersonal diagnosis and treatment of personality disorders. New York: Guilford Press, copyright Guilford Press, and from: Benjamin (1987), Use of the SASB dimensional model to develop treatment plans for personality disorders, I: Narcissism. Journal of Personality Disorders, 1, 43-70, copyright Guilford Press. 